\title{
GERAKAN ISLAM INDONESIA: MENGURAI BELENGGU, MEMBANGUN PERADABAN*
}

\author{
Mohammad Syifa A. Widigdo \\ Magister Studi Islam \\ Universitas Muhammadiyah Yogyakarta \\ Email:syifamin@gmail.com
}

\begin{abstract}
Abstrak
"Gerakan Islam Indonesia (GII) pada umumnya tidak mempunyai pengaruh, kontribusi, dan peran global yang berarti meskipun kiprah dan kontribusinya di tingkat nasional tidak perlu disangsikan lagi. Kalaupun ada bagian dari GII yang mempunyai jaringan internasional, mereka berada dalam posisi inferior karena hanya memosisikan dirinya sebagai cabang, proksi, atau simpatisan dari organisasi Islam internasional. Akibatnya, GII tidak saja hanya menjadi gerakan lokal atau gerakan proksi organisasi transnasional, tapi juga tidak sanggup menghadapi tantangan global yang semakin kompleks. Dalam artikel ini, saya berusaha memetakan kelemahan dan keterbatasan GII tersebut dan menyajikan beberapa tawaran jalan keluarnya. Salah tawaran solusinya adalah bahwa Gerakan Islam se-Asia Tengara penting untuk berkolaborasi dan bergerak secara aktif sehingga Islam di Asia Tenggara tidak lagi dianggap sebagai pinggiran. Sebab, Gerakan Islam di Asia Tenggara mempunyai cukup potensi dan modal untuk menjadi salah satu pusat peradaban Islam di dunia."
\end{abstract}

Kata Kunci: Gerakan Islam, Jaringan Internasional, Asia Tenggara, dan Tantangan Global

\begin{abstract}
Indonesian Islamic Movementsgenerally do not show a global influence and contribution although in a national level its crucial role and contribution are undeniable. Some of these movements may have an international network
\end{abstract}


but their power and authority are limited since their position is merely as a branch, proxy, or sympathizer of a certain transnational Islamic organization. As a result, these local and proxy movements are unable to cope with global challenges, which are increasingly complex. In this article, I attempt to map weaknesses and limitations of Indonesian Islamic Movements and offer some altenative solutions to cope with such weaknesses and limitations. One of the altenative solutions is for Indonesian Islamic Movements to operate and collaborate more actively with other Islamic movements in Southeast Asia. In this way, Islamic movements in Indonesia in particular, and in Southeast Asia in general, are not deemed peripheral. They have sufficient potentials and capabilities to be one of the centers of Islamic civilization.

Key words: Islamic Movement, International networking, Southeast Asia, and Global Challenge

\section{PENDAHULUAN}

Istilah "Gerakan Islam" belakangan cenderung mengalami peyorasi karena seringkali diasosiasikan dengan gerakan-gerakan yang berorientasi politik, radikal, at au meng ha 1 a 1 kanc ara - c ara kekerasan untuk mencapai tujuan politik.Peyorasi ini tampak dalam beberapa kajian dan penelitian membahas gerakan Islam, biasanya dikaitkan dengan varian radikal dari gerakan tersebut (Lihat tulisan Ahyar, Mei 2015 pp. 1-26; Ar,
September 2013; Chaq, Mei 2013). Tidak mengherankan jika kemudian gerakan Islam diidentikkan dengan gerakan politik yang bertujuan merubah tatanan rezim di tingkat nasional maupun global(Lihat Basyir, November 2016, pp. 339-

362). Sementara kegiatan dan perjuangan organisasi Islam yang menggunakan cara-cara transformatif dan damai seringkali tidak mendapatkan label sebagai "Gerakan Islam."Istilah yang dipakai untuk menggambarkan gerakan ini, misalnya, adalah "organisasi

* Sebagian (diskusi tentang tantangan dan belenggu Gerakan Islam Indonesia) dari artikel ini pernah dipublikasikan di Harian Umum Republika dengan judul "Peran Global Gerakan Islam Indonesia" pada tanggal 10 Februari 2016. Artikel ini merupakan versi yang lengkap dan mendalam, termasuk diskusi tentang solusi untuk menaklukkan tantangan dan keluar dari belenggu, yang penulis olah dari dari hasil penelitian terhadap Gerakan Islam Indonesia. 
Islam"(Lihat misalnya Collins, Oct., 2004). Padahalistilah "gerakan" dalam konteks sejarah Islam mengacu pada dua konsep, yakni pembaharuan (tajdìd) dan reformasi (iṣlāhh), yang meniscayakan makna perubahandan transformasi secara damai dan beradab.3Misalnya, gerakan pembaharuan (tajdīd) Muhammad Abduh (w. 1905) di Mesir di bidang pemikiran melalui jurnal "Al-Urwat al- Wuthqa" dan reformasi (ișlāh) di bidang pendidikan dengan memperkenalkan bidang studi sains di kurikulum Universitas al-Azhar(Hourani, 1983, pp. 130-192).Oleh sebab itu, dalam artikel ini, saya menggunakan istilah "Gerakan Islam" dalam pengertian yang luas, tidak hanya untuk gerakan yang berorientasi politik dan radikal, tapi juga (bahkan utamanya) merujuk pada organisasi dan gerakan keagamaan berorientasi sosial, intelektual, atau kultural, seperti NU (Nahdlatul Ulama), Muhammadiyah, Persis (Persatuan Islam), Hidayatullah, HMI (Himpunan Mahasiswa Islam),

Untuk mempelajari lebih lanjut perbedaan antara tajdìd, ișlāh, dan ihy $\bar{a}$, silahkan baca Abū Khalil, As'ad and Mahmoud Haddad. "Revival and Renewal." In The Oxford Encyclopedia of the Islamic World. Oxford Islamic Studies Online, http://www. oxfordislamicstudies.com/article/opr/ t236/e0682 (accessed Apr 30, 2013). dan PII (Pelajar Islam Indonesia), bahkan perguruan tinggi-perguruan tinggi Islam negeri maupun swasta. Saya melihat adanya beberapa kelamahan dalam "Gerakan IslamIndonesia (GII)" dalam konteks pembaharuan (tajdī $d$ ) dan reformasi (iṣlāh) tersebut. Di satu sisi, GII yang direpresentasikan oleh organisasi-organisasi Islam yang sudah mapan tidak mempunyai kredensial dan jaringan di tingkat internasional yang membuatnya hanya berpengaruh di tingkat nasional saja. Organisasi-organisasi Islam seperti NU, Muhammadiyah, Persis, Hidayatullah, HMI, dan PIImeskipun mempunyai pengaruh kuat di tingkat nasional, tapi pengaruh visi dan gerakan keislamannya tidak merambah ke tingkat yang lebih luas.

Di sisi yang lain, GII yang mempunyai jaringan di tingkat internasional kebanyakan hanya merupakan cabang, proksi, atau simpatisan dari gerakan-gerakan Islam transnasional. Daripada menyebarkan visi berislam yang bercorak keindonesiaan ke tingkat internasional, kelompok-kelompok Islam ini lebih bersemangat untuk menerjemahkan doktrin- doktrin induk organisasinya di tanah Indonesia. Hal ini terjadi, misalnya, dalam kasus gerakan salafi, HTI 
(Hizbut Tahrir Indonesia), berbagai kelompok simpatisan Negara Islam Iraq dan Suriah (NIIS).

Dua mainstream Gerakan Islam Indonesia sebagaimana disebutkan di atas, selain bermasalah dalam konteks skala pengaruh dan corak pemikiran, juga mempunyai kelemahan dalam cara pandang dunianya. Walhasil, Gerakan Islam Indonesia tidak saja hanya menjadi gerakan lokal atau gerakan proksi organisasi transnasional, tapi juga tidak sanggup menghadapi tantangan global yang semakin kompleks. Melalui refleksi pendek atas fenomena Gerakan Islam Indonesiakontemporer dan literatur yang saya baca, saya berusaha memetakan kelemahan dan keterbatasan GII tersebut dan menyajikan beberapa tawaran jalan keluarnya. Salah satu jalan keluarnya adalah penggalakan internasionalisasi Gerakan Islam Indonesia, minimal dimulai dari lever Asia Tenggara.

\section{TANTANGAN}

Dunia modern yang semakin terbuka dan saling terkoneksi memberikan tantangan yang kompleks baik di sektor ekonomi, politik, sosial, budaya, maupun dalam kehidupan keagamaan. Ketika proses modernisasi di hampir segala bidang merambah ke dunia muslim, kaum muslim mempunyai respon yang beragam. Sebagian dari mereka menyambut modernisasi dengan antusias. Nilai-nilai yang lahir dari rahim modernitas seperti demokrasi, kebebasan individu, kemerdekaan berfikir, persamaan hak, hak asasi manusia, ide kemajuan (the idea of progress), dan sejenisnya diadopsi dan diinjeksikan ke dunia muslim tanpa melalui proses penyaringan yang ketat. Mereka kemudian sering disebut sebagai muslim liberal.

Sebagian yang lain melihat modernitas dengan nilai-nilai dibawanya sebagai sebuah ancaman dan karenanya harus ditolak dan dilawan. Modernitas diidentikkan dengan nilai, budaya, dan politik negara Barat yang dinilai tidak cocok dengan Islam. Mereka kemudian melihat Islam tidak hanya sebagai agama tapi juga sebagai ideologi politik, ekonomi, sosial, dan budaya. Islam, bagi mereka, adalah alternatif sistem nilai yang orisinal dan solusi bagi segala permasalahan (al-Islām huwa al-hall).Beberapa kalangan bahkan berpendapat bahwa tawaran sistem dan peradaban Islam lebih superior dan bisa menggantikan peradaban Barat modern. Kalim Siddiqui(1983) bahkan menganggap bahwa kohesi peradaban Islam yang dianggap superior itu dapat 
direduksi dalam bentuk negara Islam. Dia mengakatan, "The Islamic movement, as demonstrated in earlier discussion, has the network of mosques, political culture, common memory and shared expectations necessary to hold together until a higher state of cohesion is reached. The highest stage of this cohesion is of course the Islamic state"(Siddiqui, 1983). Meskipun mereka juga menikmati dan menggunakan hasil modernitas seperti teknologi dengan berbagai produknya, namun secara umum mereka tetap resisten terhadap modernitas dengan pelbagai turunan nilai dan sistemnya. Untuk mencapai tujuan-tujuan perlawanan tersebut, sebagian memakai caracara yang persuasif dan akademik, namun sayangnya sebagian yang lain menghalalkan dan memakai cara-cara kekerasan. Karena klaim keislamannya, mereka sering disebut sebagai kelompok Islamis.

Namun demikian, sebagian kaum muslimin yang lain menghadapi modernitas dengan sikap kritis dan selektif. Di satu sisi, mereka menghargai nilai-nilai modern tersebut karena dianggap paralel dan ekuivalen dengan semangat ajaran Islam. Mereka bahkan mampu merumuskan nilainilai yang tidak saja bersesuaian dengan nilain-nilai modern tapi juga berakar dalam tradisi khazanah intelektual Islam. Di sisi yang lain, ketika nilai-nilai tersebut dipisahkan dari akar keagamaan, dijadikan jargon ideologis, dan kemudian dipaksakan melalui dominasi politik, represi ekonomi, dan kekuatan militer, mereka menolaknya. Penolakan tersebut, misalnya, terefleksi dalam resistensi mereka terhadap sekularisme sebagai sebagai faham ideologis, terhadap struktur kapitalisme atau neo -liberalisme yang eksploitatif, dan terhadap imperialisme politikmiliter negara-negara Barat di negeri-negeri muslim.

Persepsi Gerakan Islam terhadap tantangan global tergantung pada model penyikapan mereka terhadap fenomena modernitas tersebut. Bagi kaum muslim liberal, tantangan utama yang ada dalam benak mereka dalam sikap konservatif, apologetik, dan resisten dari kalangan muslim sendiri. Bagi mereka, sikap seperti itu malah menarik Islam ke dalam kemunduran dan menghambat potensi partisipasi dan kontribusi Islam bagi peradaban modern. Sementara bagi kalangan Islamis yang resisten terhadap modernitas, tantangan utama yang menghantui pikiran mereka adalah peradaban 
Barat yang menginisiasi dan respon kaum muslimin terhadap mengendalikan modernisme. Islam sebagai sebuah agama dan peradaban dianggap berlawanan secara diametral dengan peradaban Barat modern tersebut. Sedangkan bagi kalangan muslim kritis, tantangan utamanya adalah memilah bagian-bagian yang positif dari peradaban Barat modern dan khazanah Islam untuk kemudian dijembatani dan disinergikan, dan pada yang bersamaan, menanggalkan bagian-bagian yang negatifdari keduanya. Bagi mereka, masa depan dunia bukanlah konflik antar dua peradaban, Barat dan Islam, melainkan dialog dan sinergi antar berbagai tradisi peradaban di dunia.Dalam bahasa Bassam Tibbi dengan mengutip William M. Watt, hubungan antara Barat dan Islam itu tidak melulu konfliktual, tapi juga saling memberi dan menerima," The history of Islam and Europe is not only a history of mutual conquests (jihad and crusade), but is also a history of cultural encounters in the course of which decisive process of cultural borrowing took place in both sides"(Tibi, 2012, p. 17; Watt, 1991).

\section{BELENGGU}

Tipologi Gerakan Islam di Indonesia tidak jauh dari tiga bentuk tantangan modernitas sebagaimana dijelaskan di atas. Hanya saja, Gerakan Islam Indonesia (GII) mempunyai- beberapa keter- batasan dan kelemahan yang mem- buatnya tidak maksimal dalam berpartisipasi dan berkontribusi bagi konstruksi peradaban dunia, khususnya peradaban Islam. Keter- batasan dan kelemahan tersebut muncul bukan semata dipicu oleh sebab eksternal seperti proses modernisasi(Tibi, 2001),tapi lebih karena sebab-sebab internal yang saya sebut sebagai belenggu-belenggu yang menghambat dan membatasi kemampuan eksplorasi, kreatifitas, dan kebebasan mereka. Belenggubelenggu tersebut adalah, pertama, belenggu ideologis danepistemologis (pemikiran), dan kedua, belenggu pergerakan.

Gerakan Islam Indonesia yang memiliki masalah berupa belenggu ideologis dan peimikiran adalah kalangan muslimliberal dan Islamis. Kalangan liberal mengalami kesulitan untuk membayangkan masa depan peradaban tanpa menjadikan Barat sebagai referensi utama.Imajinasi mereka terjerat dan terbatas pada apa yang telah dicapai dan dimiliki oleh Barat. Barangkali mereka memang realitis karena kemajuan peradaban Barat 
bisa dilihat secara empirik di abad ke-21 ini. Namun demikian, sikap ideologisdan pemikiran yang membebek kepada Barat dan hanya berorientasi untuk menerjemahkan pencapaian Barat dalam konteks Indonesia seperti itu membuat mereka tidak kreatif untuk mencari referensi lain dalam konteks pembangunan peradaban di masa depan. Hal yang serupa terjadi pada kalangan Islamis. Mereka secara ideologis dan epistemologis menjadikan pencapaian masyarakat Islam di masa lalu sebagai rujukan utama. Bahkan, mereka tidak bisa melepaskan imajinasi dan pemikiranya dari bayangan kejayaan masa lalu untuk dibang- kitkan kembali di masa kini atau masa depan. Idealisasi tentang kekhalifahan, generasi masa awal Islam yang saleh (salaf al-șālih), atau para imam yang terjaga dari dosa (ma ș̣um) mendominasi imajinasi dan aspirasi mereka. Sikap seperti ini tidak saja utopis tapi juga membuat mereka tidak kreatif dalam konteks menerjemahkan nilai-nilai luhur yang terpendam dalam khazanah teks dansejarah Islam dalam konteks kekinian. Mereka lebih terobsesi pada bentuk, institusi, dan struktur dari sejarah masa lalu Islam daripada isi dan nila-nilai luhur yang diwariskannya.
Kedua sikap dan pemikiran tersebut di atas, baik dari kalangan liberal maupun Islamis, mempunyai dua konsekuensi yang kontraproduktif bagi pembangunan peradaban masa depan: satu, membelenggu kemerdekaan dan kemampuan Gerakan Islam Indonesia untuk secara kreatif dan orisinal merumuskan sendiri model per-adabannya, dua, membuat Gerakan Islam Indonesia kedap rasa dan empati sehingga tidak bisa mendengar dan menyelami suasana batin masyarakat Indonesia yang bergelut dengan berbagai pemasalahannya. Oleh sebab itu, hemat saya, satusatunya yang bisa diharapkan untuk mempimpin agenda pembangunan peradaban masa depan adalah Gerakan Islam Indonesia yang kritis dan transformatif. Gerakan ini tidak saja terbuka terhadapkebijaksanaan (wisdom) dan keutamaan (virtue) baik yang datang dari Barat maupun dari khazanah teks dan sejarah masa lalu Islam, tapi juga, mempunyai kemampuan untuk menyelami suasana batin masyarakat Indonesia karena mereka memang bergelut dengan permasalahan masyarakat dalam aktivitas kesehariannya.

Hanya saja, Gerakan Islam Indonesia yang kritis tersebut mempunyai belenggunya tersendiri. Tidak seperti kalangan liberal dan 
Islamis yang mempunyai jaringan internasional kuat karena afinitas ideologis dan epistemologisnya, GII yang kritis dan transformatifbelum ditunjang oleh kredensial, integritas, dan jaringan untuk dapat berpartisipasi dan berkontribusi secara global. Itulah yang menjadi belenggu pergerakannya.

Berbeda dengan jenis belenggu GII yang bersifat kritis-transformatif, GII yang berkarakter liberal dan Islamis memiliki belenggu pergerakannya tersendiri. Mereka tidak terlalu memiliki masalah dengan jaringan. Masalah mereka terletak pada integritas dan kredensial sebagai Gerakan Islam yang mempunyai jiwa keislaman dan keindonesiaan. Gerakan kalangan liberal menempatkan Barat sebagai pusat orientasi per- gerakan dan Indonesia sebagai cabangnya. Pergerakan mereka umumnya berada di level pemikiran dan ditujukan hanya untuk mendapatkan legitimasi, afirmasi, atau anggukan dari Barat bahwa mereka telah menjadi pegerakan Islam yang modern dan liberal di tanah air. Orientasi keislaman dan keindonesiaan seringkali absen dari agenda-agenda pemikiran dalam pergerakannya. Gerakan kaum Islamis memiliki belenggu yang serupa. Mereka menjadikan
Timur Tengah, khususnya Jazirah Arab bagi kalangan Sunnī dan Iran bagi kalangan Syi'ah, sebagai episentrum gerakan. Kiprah mereka di Indonesia tidak lebih dari sekedar menjadi simpatisan, cabang, atau proksi bagi pusat pergerakan mereka di Timur Tengah. Dalam istilah Bassam Tibi, mereka adalah tumpahan (spill-over) dari problematika dan pergerakan di Timur Tengah yang dianggap sebagai pusat (the core)(Tibi, 2012, p. 22).Oleh sebab itu, tidak mengherankan jika pergerakan mereka umumnya mengandung orientasi politik dan hanya ditujukan untuk mendapatkan legitimasi, afirmasi, dan pengaminan dari kelompokkelompok induk mereka di Timur Tengah.

GII yang berkarakter kritistransformatif tidak memiliki problem atau belenggu sebagaimana yang dimiliki oleh gerakan liberal dan Islamis dalam konteks kehausan untuk mendapat legitimasi, afirmasi, dan persetujuan dari pihak luar. Mereka telah memiliki legitimasi, afirmasi, dan dukungan sosialmaupun kultural dari masyarakat Indonesia. Mereka juga telah bergelut dengan teks, sejarah, dan menjadi bagian tak terpisahkan dari kehidupan masyarakat Islam di dunia. Hanya saja, sebagaimana 
yang tadi dikemukakan, masalah utama bagi mereka adalah minim-nya tingkat partisipasi dan kontribusi mereka di tingkat global. Masalah ini diperparah dengan belenggu-belenggu yang membatasi pergerakan dan kiprah mereka, seperti krisis kredensial, integritas, dan jaringandi dalam pergerakan mereka. Namun, dalam hal krisis kredensial dan integritas, mereka berbeda dengan kalangan liberal dan Islamis. Jika kalangan liberal mengalamai krisis kredensial dan integritas dalam konteks komitmen keislaman dan kalangan Islamis dalam konteks komitmen keindonesiaan,maka krisis kredensial dan integritas yang dimiliki oleh gerakan Islam kritis berada dalam konteks pergaulan global. Mereka masih dianggap sebagai pemain figuran. Keislaman mereka masih dianggap Islam yang pinggiran dan inferior(Tibi, 2012,

p. 22).Bagaimana cara mengatasi belenggu-belenggu gerakan Islam Indonesia yang seperti ini?

\section{PINGGIRAN MEMBANGUN} KREDENSIAL， INTEGRITAS, DAN JARINGAN

Pada awal Islam, dari zaman Nabi hingga al-Khulafā' alRāshidūn (622-661), pusat keagamaan dan kekuasaan berada di Madinah. Kota -kota lain dianggap sebagai kota pinggiran yang tidak mempunyai otoritas keagamaan maupun kekuasaan. Setelah berhasil merebut kekuasaan dari tangan Alī b. Abī Tālib pada tahun 661, Mu'āwīyah mendirikan Daulah Umayyah yang berpusat di Damaskus, Syria, hingga tahun 750. Pusat kekuasaan dan keagamaan pun berpindah ke sana. Kota-kota lain dianggap sebagai pinggiran dan tidak punya signifikansi kekuasaan dan keagamaan yang setara dengan pusat. Termasuk Mekah dan Madinah, Kufah, dan Basrah. Pesaing-pesaing utama politik yang tinggal di kota-kota pinggiran tersebut dihabisi, seperti Husayn b. 'Alī di Kufah pada tahun 680 dan 'Abdullāh b. Zubayr di Mekah pada tahun 692. Namun demikian pusatpusat kajian kagamaan di luar Damaskus mulai merebak. Hasan alBasri (642-728) mempunyai pusat kajian yang ramai dan berpengaruh di Basrah. 'Abdullāh b. 'Abbās (w. 687), 'Abdullāh b. 'Umar (w. 693), dan Mālik b. Anas (711-795) mengembangkan tradisi kesarjanaan tersendiri di Mekkah dan Madinah. Abū Hanīfah (699-

767) merumuskan dan menularkan metodologi hukum tersendiri di Kufah. Tradisi keilmuan yang berkembang baik di kota-kota 
pinggiran kekuasaan tersebut membuatnya tidak kehilangan signifikansi keagamaan. Kota-kota tersebut tetap mempunyai legitimasi keislaman yang setara, bahkan beberapa lebih kuat, dibandingkan dengan Damaskus.

Kecenderungan seperti ini terus terjadi ketika pusat kekuasaan beralih ke Daulah Abbasiyah di tahun 750 hingga 1258. Pusat kekuasaan dunia Islam boleh saja berada di Baghdad dan sebagian dibagi dengan Dinasti Fatimiyyah yang berpusat di Kairo (dengan kekuasaan meliputi Afrika Utara dan Mesir) dan Dinasti Umayyah di Andalusia yang berpusat di Kordoba. Namun demikian, kotakota baru di luar lingkaran pusat kekuasaan juga berkembang. Di wilayah Khurāsān, terdapat Nīshāpūr, Herat, Marw, dan Balkh. Di Asia Tengah, terdapat kota-kota seperti Samarqand, Bukhara, dan Khawarizm. Di Andalusia, selain Cordoba juga ada Granada. Kotakota di pinggir kekuasaan tersebut tidaklah inferior terhadap pusatpusat kekuasaan. Sebagian menjadi kota perdagangan yang strategis dan ramai, seperti Samarqand dan Nishapur, salah satunya karena memang berada di jalur perdagangan Silk Road. Namun demikian, selain menjadi kota perdagangan, kota-kota tersebut juga menjadi pusat-pusat keilmuan yang menjadi tiang penyangga zaman keemasan Islam. 'Ulamā' di bidang ilmu al-Qur'an, Hadīth, fiqih, kalām, ta'awwuf, filsafat, dan kesusastraan kebanyakan berasal dari kota-kota pinggiran tersebut. Demikian pula dengan para ilmuwan di bidang matematika, optik, kimia, astronomi, kedokteran dan ilmu-ilmu rasional lainnya. Mereka banyak yang berasal dan berkarya di wilayah luar pusat kekuasaanitu. Dinamika kesarjana- an dan perdagangan semacam inilah yang membuat kotakota tersebut tetap memiliki kredensial di bidang kesarjanaan Islam, integritas di bidang ekonomi, dan jaringan yang kuat baik di bidang keilmuan maupun ekonomi. Dengan demikian, daerah-daerah pinggiran tersebut mempunyai daya tawar, tidak dipandang sebelah mata, dan mampu berkontribusi secara signifikan dalam konteks kejayaan peradaban Islam di abad pertengahan(Hodgson,

1974a, 1974b).

Narasi sekilas tentang kotadan wilayah pinggiran dala sejarah Islam tersebut memberi gambaran tentang peran dan sumbangan kota-kota itu terhadap pembangunan peradaban. Kota-kota tersebut 
tidak hanya menjadi salah satu tiang kuat penyangga peradaban. Beberapa kotabahkan menjadi pusat kesarjanaan, ekonomi, dan politik yang baru, termasuk Baghdad, Kairo, Cordoba, dan Samarqand. Catatan sejarah ini dapat dijadikan inspirasi dan pijakan bagi negerinegeri di luar pusat dan sumber diskursus keislaman di masa kini, termasuk Indonesia. Gerakan Islam di Indonesia tidak perlu meminta dan mencari legitimasi keberagamaan dan kesarjanaan Islam dari negeri -negeri di Timur Tengah. Mereka bisa mengakses sendiri sumber-sumber keislaman dari yang primer seperti al-Qur'an dan Sunnah hingga yang sifatnya literatur kesarjanaan seperti yang ditulis oleh para sarjana dan 'ulamā'. Oleh sebab itu, salah satu hal yang penting dilakukan adalah pembangunan kredensial kesarjanaan Islam di Indonesia, terutama melalui tradisi riset dan publikasi yang kuat. Hal ini penting dilakukan agar para sarjana Islam di Indonesia dapat berdiksusi secara setara dengan koleganya di negaranegara Timur Tengah maupun Barat dan memberikan kontribusi yang penting bagi kesarjanaan Islam di tingkat dunia.

Hanya saja, tradisi kesarjanaan Islam saja tidak cukup. Pem- bangunan kredensial dan integritas keislaman di Indonesia juga perlu ditopang oleh kredensial dan integritas di bidang-bidang yang lain, terutama di bidang ekonomi, ilmu pengetahuan, sosial, serta politik. Negara-negara Islam di kawasan Timur Tengah cenderung menganggap negeri-negeri Islam di luar kawasan mereka sebagai kurang Islam (less Islamic) dan oleh karenanya mereka perlu diislamkan lagi. Anggapan semacam ini akan luntur dengan sendirinya apabila negeri-negeri Muslim di luar Timur Tengah itu mempunyai kredensial dan integritas di bidang ekonomi, ilmu pengetahuan, sosial, serta politik. Pengalaman hubungan antara negara-negara Timur Tengah dengan negara-negara Barat mengajarkan tentang pola hubungan yang penuh penghormatan itu. Timur Tengah lebih respek (untuk tidak mengatakan, inferior) terhadap negara-negara Barat daripada negara-negara Muslim di luar kawasan Timur Tengah bukan karena bertambahnya jumlah populasi Muslim atau majunyakesarjanaan Islam di Barat, melainkan, karena sumber daya ekonomi, keunggulan ilmu pengetahuan, tatanan sosialnya yang relatif adil dan damai, dan 
kekuatan politiknya.4Oleh sebab itu, agar peradaban Islam di Indonesia mempunyai daya tawar, posisi sejajar, dan tidak lagi dianggap remeh, figuran, inferior, atau lemah oleh koleganya di Timur Tengah dan di belahan dunia yang lain, maka Gerakan Islam Indonesia dituntutuntuk menjadi peolopor bagi pembangunan bukan saja iklim dan tradisi kesarjanaan yang kuat, tapi juga kekuatan ekonomi,

$4 \quad$ Hal ini tercermin dalam kenyataan bahwa negera-negara Timur Tengah mengirimkan pelajar-pelajar terbaiknya untuk belajar di Barat. Para sarjana dan professional terbaik mereka juga banyak yang berkarir di negera-negara Barat. Bahkan, para pembesar politik maupun tokoh intelektual mereka pun kebanyakan pernah menempuh pendidikan di Barat. Ini menunjukkan betapa mereka mempunyai respek yang besar terhadap kemajuan peradaban dan perkembangan ilmu pengetahuan di Barat. Bukan itu saja, beberapa negara di Timur Tengah, seperti Qatar, UEA, dan Arab Saudi bahkan membuka cabangcabang perguruan tinggi Barat di negara mereka atau merekrut secara besarbesaran para pengajar lulusan Barat untuk mengajar di perguruan tinggi mereka. Hal yang sama terjadi dalam konteks politik dan ekonomi. Ketergantungan mereka terhadap Barat, terutama Amerika dan sekutunya, sangat besar baik dalam konteks menyelesaikan konflik di wilayahnya, mengkonsumsi minyak yang diproduksinya, atau untuk membangun gedung, hotel, dan tokotoko di kawasannya. keunggulan institusi pendidikan, keteraturan sosial, dan stabilitas politik.

Dalam konteks Indonesia kini, stabilitas politik Indonesia dan negara-negara yang berpenduduk Muslim di kawasan Asia Tenggara jauh lebih baik daripada kondisi politik di negara-negara Timur Tengah. Gerakan Islam Indonesia tidak perlu untuk terobsesi di sektor politik, apalagi dengan hanya glorifikasi struktur politik masa lalu (baca: khiläfah atau imāmah). Pada dasarnya,yang diperlukan di sektor inihanyalah terusmerawat demokrasi sehingga proses pergantian politik dapat berlangsung secara damai dan problem-problem kerakyatan dapat diselesaikan. Pekerjaan rumahGII kemudian tinggal mengerucutpada tigabidang, yaitu membangun kekuatan ekonomi, mewujudkan tatanan sosial yang adil dan damai, dan keunggulan ilmu pengetahuan.

Gerakan Islam di Indonesia sebenarnya mempunyai kapasitas yang cukup untuk dapat mengerjakan dan menyelesaikan pekerjaaan rumah tersebut. Untuk hal yang pertama, yakni membangun kekuatan ekonomi, gerakan Islam di Indonesia mempunyai lembaga perbankan syariah, keuangan mikro, pengelola zakat atau wakaf, 
dan bahkan asosiasi pengusaha yang dapat menjadi aktor utama dalampemberdayaan

ekonomi umat dan bangsa.

Sementara untuk hal yang kedua, yaitu mewujudkantatanan sosial yang adil dan damai, gerakan Islam di Indonesia juga memiliki organisasiorganisasi Islam yang mapan untuk dijadikan sebagaiujuk tombak dalam mewujudkan- cita- cita sosial tersebut. Organisasi masyarakat (ormas) keagamaan seperti NU, Muhammadiyah, Persis, dan Hidayatullah menjadi aktor penting tidak saja dalam menyebarkan pemahaman- keagamaan yang moderat dan damai, tapi juga menjadi pemain utama dalam membangun hubungan yang saling menghargai dan menghormati antar agama serta membela hak-hak kelompok yang dianggap sesat dan minoritas. Organisasi pelajar dan mahasiswa seperti HMI, PMII (Pelajar Mahasiswa Islam Indonesia), dan IMM (Ikatan Mahasiswa Muhammadiyah)telah menjadi organisasi perkaderan dan perjuangan yang teruji. Mereka tidak saja telah berhasil mendidik generasi muda Indonesia untuk menjadi pemimpin di berbagai sektor ke- hidupan. Lebih dari itu, mereka juga merupakan pemain utama dalam konteks mengembangkan pemahaman keislaman yang progresif dan transormatif di kalangan generasi muda Islam Indonesia. Sementara organisasi non-pemerintah (ornop) atau yayasan, seperti The Wahid Institute, Maarif Institute, Fahmina Institute, dan LSAF (Lembaga Agama dan Filsafat) berperan penting dalam konteks mengadvokasi kelompokkelompok yang terpinggirkan, hakhak perempuan, dan pluralisme kepercayaan berdasarkan pemahaman- Islam yang progresif dan transformatif.

Untuk hal yang ketiga, yakni membangun keunggulan ilmu pengetahuan,- gerakan Islam di Indonesia juga mempunyai banyak institusi pendidikan dan lembaga penilitian yang dapat didorong untuk menjadi pusat-pusat keunggulan ilmu pengetahuan. Selain pesantren, madrasah, dan sekolah Islam, Indonesia juga mempunyai perguruan tinggi Islam yang negeri (i.e. UIN, IAIN, STAIN) maupun swasta (e.g. Perguruan Tinggi Muhammadiyah, UII, Unisma, UMI) yang tersebar di seluruh pelosok negeri. Lembagalembaga penelitian yang terkoneksi dengan perguruan tinggi (e.g. PPIM UIN Syarif Hidayatullah) maupun di luar perguruan tinggi (e.g. The Habibie 
Center) juga ada.5 Yang diperlukan selanjutnya adalah pembangunan kapasitas dan kompetensi mereka agar dapatmendidik, meneliti, dan berkarya di level yang setara, atau bahkan, mengungguli, pusat-pusat keunggulan dunia. Di samping perlu keberpihakan dan keterlibatan pemerintah, mereka juga perlu untuk membuka jaringan dan berkolaborasi dengan pusat-pusat keunggulan dunia. Dengan demikian, diharapkan, kapasitas dan kompetensi mereka dapat meningkat dan karya-karya mereka dapat memberi sumbangan yang berarti bagi kesarjanaan dan kemanusiaan dalam skala global.

\section{KESIMPULAN:}

SINERGI UNTUK PERADABAN

Dengan sumber daya gerakan Islam di Indonesia seperti yang dikemukakan di atas, seharusnya umat Islam Indonesia melalui gerakan -gerakan tersebut di atas mampu mengambil peran aktif dan strategis dalam konteks

\footnotetext{
5 Berikut kepanjangan dari beberapa singkatan yang disebut di atas: UIN (Universitas Islam Negeri), IAIN (Institut Agama Islam Negeri), STAIN (Sekolah Tinggi Agama Islam), UII (Universitas Islam Indonesia) di Yogyakarta, Unisma (Universitas Islam Malang), UMI (Universitas Muslim Indonesia) di Makassar, PPIM (Pusat Pengkajian Islam dan Masyarakat).
}

pembangunan peradaban. Tidak perlu di tingkat dunia tampaknya masih terlalu muluk dan utopis. Partisipasi dan kontribusi Gerakan Islam di Indonesia dapat dimulai dengan membangut jaringan yang kuat di lingkup negara-negara Asia Tenggara. Mungkin selama ini asosiasi jaringan gerakan Islam di Asia Tenggara dilekatkan dengan kelompok-kelompok radikal yang menghalalkan kekerasan. Jaringan kelompok-kelompok radikal (Islamis) tersebut akan kalah dan terhenti dengan sendirinya jika gerakan Islam yang kritis dan transformatif di Asia Tenggara dapat berkolaborasi dan bersinergi secara struktural maupun kultural di sektor ekonomi, sosial, serta ilmu pengetahuan.Jaringan formal secara ekonomi telah terbuka melalui pemberlakuan Masyarakat Ekonomi Asean (MEA) pada akhir tahun 2015. Masyarakat Asia Tenggara ke depan akan semakin terkoneksi dan terintegrasi antara yang satu dengan yang lain. Kenyataan ini memberikan kesempatan bagi gerakan Islam di Indonesia. Mereka dapat mempelopori kolaborasi dan sinergi elemen-elemen masyarakat dan perguruan tinggi untuk meningkatkan kompetensi diri, menciptakan karya unggul di bidang ilmu pengetahuan dan teknologi, 
dan sekaligus memberi sumbangan penting bagi peradaban dunia.

Di samping itu, kolaborasi dan sinergi pusat-pusat keunggulan yang dipelopori oleh gerakan Islam di Asia Tenggara juga diharapkan dapat mengatasi beberapa tan- tangan yang dihadapi oleh umat Islam selama ini. Tantangan internal masyarakat Asia Tenggara, seperti kemiskinan, menjadi masalah yang diharapkan dapat diatasi dengan pembukaan MEA. Namun tantangan-tantangan lain, terutama ideologi kekerasan yang dibawa oleh sebagian gerakan Islamis dari Timur Tengah dandereligiusasi6pemikiran dan budaya yang diimpor kalangan liberal dari dunia Barat, bukan menjadi domain dan konsentrasi MEA untuk menyelesaikannnya. Dalam hal ini, gerakan Islam di Asia juga dapat mengambil peran penting. Jika organisasi Islam dan pusat-pusat keunggulan Asia Tenggara berkomitmen danterus mengeksplorasi hubungan antara Islam denganpemahaman moderat

\footnotetext{
6 Saya memilih untuk memakai istilah "dereligiusisasi" daripada "sekularisasi" dengan pemikiran bahwa yang paling dikhawatirkan dari proses sekularisasi adalah tersingkirnya aspek-aspek religius dari nafas kehidupan masyarakat. Penghargaan terhadap etika dan norma agama dihilangkan dan digantikan dengan etika dan norma yang bersifat positivis dan materialistik.
}

(wasa'iyyah ) dalam beragama, pluralisme keagamaan dan kepercayaan di Asia Tenggara, hakhak kaum minoritas, pemberdayaan dan pembelaan perempuan, serta ekonomi kerakyatan dan pemberdayaan, maka mereka akan mendapatkan dua manfaat sekaligus. Pertama, mereka akan dapat mencegah dan mengobati penyakit radikalisme dalam gerakan Islam melalui pemahaman keagamaan yang moderat dan, kedua, menangkal penyingkiran nilai, etika, dan norma keagamaan dari masyarakat melalui penyajian Islam di Asia Tenggara yang dapat berdialog dengan modernitas dan realita yang terus berkembang.

Pada akhirnya, diharapkan, masyarakat Islam di Asia Tenggara mampu menampilkan peradaban tersendiri. Yaitu, peradaban yang menunjukkan bahwa Islam di Asia Tenggara dapat berjalan beriringan dengan demokrasi politik dan ekonomi, mendorong keunggulan ilmu pengetahuan dan teknologi, menghargai keragaman agama dan kepercayaan, melindungi kaum minoritas, membela hak-hak kaum perempuan, serta dapat hidup harmonis dalam perbedaan sekte, etnis, dan agama. Dengan demikian, jika peradaban Islam di belahan dunia lain, misalnya 
Timur Tengah, ingin belajar tentang hal-hal tersebut di atas, mereka akan pergi belajar ke pengalaman paradaban Islam di Asia Tenggara. Saat itulah, peradaban Islam yang awalnya dianggap pinggiran, akan sejajar atau bahkan mengungguli peradaban yang menganggap dirinya sebagai pusat Islam.

\section{Daftar Pustaka}

Ahyar, M. (Mei 2015 ). Membaca

Gerakan Islam radikal dan

Deradikalisasi Gerakan Islam.

Walisongo, 23(1), 1-26.

Ar, E. H. (September 2013). Pola Gerakan Islam Garis Keras di Indonesia. Jurnal Khatulistiwa - Journal Of Islamic Studies, $3(2)$.

Basyir, K. (November 2016).

Ideologi Gerakan Politik Islam di Indonesia. Al-Tahrir, 16(2), $339-362$.

Chaq, M. D. u. (Mei 2013). Pemikiran Hukum Gerakan Islam Radikal. Tafaqquh, 1(1), 16-42.

Collins, E. F. (Oct., 2004). Islam and the Habits of Democracy: Islamic Organizations in PostNew Order South Sumatra. Indonesia(78), 93-120.

Hodgson, M. G. S. (1974a). The Venture of Islam 1: Conscience and History in a World of Civilization (Vol. 1: The Classical Age of Islam). Chicago: The University of Chicago Press. Hodgson, M. G. S. (1974b). The Venture of Islam 2. Chicago: The University of Chicago Press.

Hourani, A. (1983). Arabic Thought in the Liberal Age, 1798-1939. Cambridge:

Cambridge University Press.

Siddiqui, K. (1983). Struggle for the supremacy of Islamsome critical dimensions. In K. Siddiqui (Ed.), Issues in the Islamic Movement 1981-82. London: The Open Press Limited.

Tibi, B. (2001). Islam Between Culture and Politics. New York: Palgrave.

Tibi, B. (2012). Islam in Global

Politics: Conflict and crosscivilizational bridging. New York: Routledge.

Watt, W. M. (1991). MuslimChristian Encounters. New York: Routledge. 